\title{
ANALYSIS OF HAZARD AREAS ASSOCIATED WITH TOXIC CLOUD RELEASES BY PIPELINES
}

\author{
R.V. GAGLIARDI, C. ANDENNA \& L. CITRO \\ Department of Production Plants and Human Settlement-ISPESL, Italy.
}

\begin{abstract}
The consequence assessment of a major accident involving a release of toxic gas by a pipeline is usually performed through the evaluation of the associated hazard area, which is an area where the concentration of the toxic substance exceeds a fixed threshold level and induces harmful effects in people and the environment; its extension represents a significant source of information required for the development of both safety and security strategies associated with dangerous pipelines. Since the threshold level adopted in the calculation strongly affects the extent of this hazard area, the purpose of this paper is to analyse such influence and the potential implications on the decisional process concerning prevention, preparedness and response actions in the case of major accidents. The paper describes the methodological approach adopted for this purpose, as well as the main results obtained using the threshold levels most commonly applied in the industrialized countries. Although the estimate of the hazard areas involves a high level of uncertainty, this study aims at supporting the development of pipeline safety and security strategies, thus increasing the overall safety level in this vital sector.

Keywords: consequence assessment, major accident, pipeline safety and security, toxic cloud dispersion.
\end{abstract}

\section{INTRODUCTION}

The transport of chemicals in pipelines is a significant technological solution applied in various branches of the energy and industrial sectors. Pipelines are generally considered the safest and most economical way of carrying large quantities of dangerous substances (flammable, explosive and/or toxic). However, as the analysis of transmission pipeline accidents has demonstrated [1], they can potentially constitute the threat of a major accident, as defined in the European Directive 96/82/CE "Seveso II" [2], the consequences of which can seriously affect human health and the environment in the vicinity of the pipelines. Moreover, in the light of the recent escalation of the terrorist threat against critical infrastructures, such as transport or energy networks, pipelines can also be considered a vulnerable target that require appropriate security solutions for their protection, as required by the recent European Directive 2008/114/EC [3]. From this point of view, pipelines carrying dangerous substances represent a subject that necessarily requires a harmonious integration of safety and security strategies aimed at reducing the likelihood and impact of potential accidents. An issue that should be addressed in both sectors, for example, is the assessment of the areas potentially affected by the consequences of a dangerous substance release, whether caused by accident or deliberate act of terrorism. This evaluation can be considered essential for the improvement of adequate safety strategies, such as the development of emergency plans or land-use planning measures in the vicinity of dangerous pipelines, as well as for the implementation of security solutions for the protection of critical infrastructures, as required by the operator's security plan. Therefore, in this paper, the potential impact of a release of toxic substance by pipelines has been investigated in terms of hazard area, which is an area where the concentration of a toxic substance exceeds a fixed threshold level and induces harmful effects in people and the environment; the choice of the toxic release is due to the fact that this event has the potential to generate impact areas bigger than those associated with flammable or explosive substances releases. In particular, since the 
threshold level adopted in the calculation strongly affects the extent of this hazard area, the purpose of this paper is to analyse such influence, highlighting its potential implications on the decisional process concerning emergency needs. The different steps carried out for this purpose, combining qualitative information and quantitative techniques of risk analysis, are presented in this paper. In particular, as a preliminary stage, a critical review of the threshold levels most commonly applied in the industrialized countries was conducted in order to investigate the full range of potential health effects. Then, in order to analyse the consequences of a toxic release by pipeline; a hazard model was developed in two steps: first estimating the gas mass flow rate, then evaluating the consequent atmospheric dispersion of the toxic cloud. Finally, on the basis of the aforementioned models, the quantitative assessment of a hazard area covered by the toxic cloud was carried out through a sequence of simulations employing a commercially available software package, and a critical review of the results obtained was performed. All of the above steps shall be illustrated in the following sections.

\section{THRESHOLD LEVELS}

In the case of a major accident involving a toxic release, the decisional process concerning the selection of the most appropriate preventive, mitigating and/or emergency measures (such as, the structuring of community evacuation plans, ensuring proper protective equipment, etc.), requires an accurate choice of which threshold value must be used as the level of concern to protect public health. Health risks from toxic exposure can range from mild irritation that subsides immediately upon the cessation of exposure, to acute reversible effects that might require medical intervention, to long-term irreversible serious health effects, and, in the worst case scenario, immediate or early death. In general, threshold levels can be summarized into three distinct categories: (1) guidelines for occupational health, (2) guidelines specifically developed for emergency response planning, and (3) fatality data derived from animal studies. Due to their long exposure times and applicability for chronic exposure, the occupational health values are not generally employed for assessing consequences of accidental hazardous materials releases, with the exception of the immediately dangerous to life and health (IDLH) limit [4]. These are based on conditions that pose immediate danger to life or health using an exposure time of $30 \mathrm{~min}$. Workers should not be in an IDLH environment for any length of time unless they wear appropriate personal protective equipment. For emergency response application the Emergency Response Planning Guidelines (ERPG) values [5] and Acute Exposure Guideline Levels (AEGL) [6] health criteria are widely considered to be the best values available. The former are intended to provide estimates of concentration ranges below which there are no effects on the health of exposed individuals according to three different levels with a common denominator of $1 \mathrm{~h}$ contact duration. The latter represent concentration ranges above which there are effects on the health of exposed individuals according to three levels of effect severity, each developed for five exposure periods: $10 \mathrm{~min}, 30 \mathrm{~min}, 1 \mathrm{~h}, 4 \mathrm{~h}$ and $8 \mathrm{~h}$. In considering substances for which AEGL or ERPG values are not available, health criteria can be derived using a lethal concentration values $\left(\mathrm{LC}_{50}\right)$ [7] representing the concentration at which $50 \%$ of the exposed population will die. Table 1 shows the reference values corresponding to the threshold level mentioned above for carbon monoxide and fluorine. These substances have been chosen as a case study, in order to take into account different toxicity levels (respectively toxic and very toxic, as required by the Seveso legislation), as well as different densities of released gas compared with air (lighter and heavier than air).

It is worth mentioning that several research projects have been currently undertaken for developing additional acute exposure value to meet emergency needs and cover more 
Table 1: Threshold values for carbon monoxide and fluorine.

\begin{tabular}{lcc}
\hline $\begin{array}{l}\text { Threshold level/ exposure } \\
\text { time (min) }\end{array}$ & $\begin{array}{l}\text { Carbon monoxide (ppm) } \\
\text { Toxic gas }\end{array}$ & $\begin{array}{l}\text { Fluorine (ppm) Very } \\
\text { toxic gas }\end{array}$ \\
\hline IDLH/30 & 1200 & 25 \\
LC50/30 & 1900 & 224 \\
AEGL-1/60 & - & 1.7 \\
AEGL-2/60 & 83 & 5 \\
AEGL-3/60 & 330 & 13 \\
ERPG-1/60 & 200 & 0.5 \\
ERPG-2/60 & 350 & 5 \\
ERPG-3/60 & 500 & 20 \\
\hline
\end{tabular}

chemical substances, also improving consistency in parameters used in consequences assessment of major accident hazards [8].

\section{THEORETICAL BACKGROUND}

A hazard model has been defined for the evaluation of the hazard areas consequent to a toxic release by pipelines. This model consists of two parts, which are, respectively, the gas mass flow rate, which predict the rate at which the chemicals are released to the atmosphere, and the atmospheric dispersion model, which calculate the dilution and spread of this material as it moves downwind the source; basis of each model, as well as the underlying assumptions, are described in the following two sections. The former is strongly influenced by the property and quantities of the released substance, the operating and release condition (pressure and temperature, hole size and release duration); the latter depends on meteorological conditions (wind speed and direction, atmospheric stability class) and external factors (topography, the presence of obstacles in the vicinity). Since the strong influence of all these parameters on the extent of the hazard areas has already been investigated in other sensitivity analysis studies $[9,10]$, the focus of this study is rather the analysis of the implications of the threshold levels on the same extent.

\subsection{Gas mass flow rate}

According to the consolidated models widely discussed in the literature [11], the initial maximum gas mass flow rate at the hole can be obtained from the continuity equation of the ideal gases law for isentropic expansion. If the pressure in the pipeline just inside an opening to the air is about 1.9 times greater than the atmospheric pressure, the flow will be sonic and can be estimated by the following equation:

$$
q_{s, 0}=C_{d} A \sqrt{\rho_{0} P_{0} \gamma\left(\frac{2}{\gamma+1}\right)^{\left(\frac{\gamma+1}{\gamma-1}\right)}}
$$

It is worth noting that, in order to take into account the most conservative assumptions, the model has been developed to describe the full-bore rupture of the pipeline. Therefore, in this case, the initial maximum mass flow rate can be estimated by assuming the diameter of the 
pipe as an effective hole size. To predict the mass flow rate as a function of time, the empirical Wilson model [12] for non-stationary gas flow in pipelines after a full-bore rupture has been assumed. According to this model the mass flow rate is given by:

$$
q_{s, t}=\frac{q_{s, 0}}{\left(1+\frac{Q_{0}}{t_{B} q_{s, 0}}\right)}\left(\frac{Q_{0}}{t_{B} q_{s, 0}} e^{\left(\frac{-t}{t_{B}}\right)}+e^{-t t_{B}\left(\frac{q_{s, 0}}{Q_{0}}\right)^{2}}\right)
$$

Expressing the initial total mass $\mathrm{Q}_{0}$ in the pipeline as:

$$
Q_{0=} \rho_{0} A_{p} l_{p}
$$

and calculating the time constant $t_{B}$ through the following equation (4):

$$
t_{B}=\frac{2}{3} \frac{l_{p}}{u_{s}} \sqrt{\frac{\gamma f l_{p}}{d_{p}}}
$$

the mass flow rate $q_{s}(t)$ can be estimated at any time $t$ after the full- bore rupture of the pipeline by equation (2).

\subsection{Atmospheric dispersion}

The second part of the hazard model describes the atmospheric toxic cloud dispersion. The distances where the toxic concentrations exceed the reference threshold levels can be estimated using as input parameters the mass flow rate, defined in the previous section. According to the type of gas, respectively neutral ore dense, different dispersion models must be used [12].

For neutral gas the Gaussian plume models (GPM) are usually employed. The equation for the Gaussian plume is a function of the mass flow rate for unit time, the mean wind speed, the crosswind and vertical standard deviations $\left(\sigma_{y}(\mathrm{x})\right.$ and $\left.\sigma_{z}(\mathrm{x})\right)$ and the height source $\left(h_{s}\right)$.

The contaminant concentration at position $\mathrm{x}, \mathrm{y} \mathrm{e} \mathrm{z}, C^{z}(x, y, z)$, is given by:

$$
C(x, y, z)=\frac{q_{s}}{2 \pi \mathrm{v} \sigma_{y} \sigma_{z}}=e^{\frac{1}{2}\left(\frac{y}{\sigma_{y}}\right)^{2}}\left(e^{-\frac{1}{2}\left(\frac{z-h_{s}}{\sigma_{z}}\right)^{2}}+e^{-\frac{1}{2}\left(\frac{z-h_{s}}{\sigma_{z}}\right)^{2}}\right)
$$

The dispersion parameters of the toxic cloud, $\sigma_{y}$ and $\sigma_{z}$, are functions of the downwind distance, the atmospheric stability classes and the roughness of the terrain. For the estimation of $\sigma_{y}$ and $\sigma_{z}$, Pasquill-Gifford curves have been used, and have been fitted with approximate equations shown in scientific literature [13]. For dense gas the SLAB model is used to simulate the atmospheric dispersion of the toxic substance. The plume model is based on conservation equations of mass, momentum, energy and species. The three-dimensional volume concentration distribution $C(x, y, z)$ is obtained by assuming the following crosswind profile:

$$
C(x, y, z)=2 B h_{\mathrm{c}} C(x) C_{1}(y, b, \beta) C_{2}\left(z, Z_{c}, \sigma\right)
$$

where $C_{1}(y, b, \beta)$ and $C_{2}\left(z, Z_{c}, \sigma\right)$ are horizontal and vertical profile functions, $\mathrm{C}(\mathrm{x})$ is the crosswind-averaged volume concentration. 


\section{RESULTS AND DISCUSSION}

Once the most appropriate equations describing the event were defined, the quantitative assessment of the hazard areas has been carried out through several simulations using commercially available software [14] based on the mathematical models previously described. To carry out the simulations, the input parameters corresponding to a condition, as close to a real accident event as possible, have been selected, examining databases storing information on pipeline accidents [15] as well as legislative provisions [16]. These parameters are summarized in Table 2. As far as the spatial dimension of the problem is concerned, it is assumed that the toxic cloud originates from a leak in the pipe according to the origin of an orthogonal reference system, in which the x-axis indicates the distance in which the cloud travels in the direction of the wind, and y-axis indicates the width of the cloud in a crosswind direction. The concentrations of toxic substance are assessed at $1.5 \mathrm{~m}$ height, corresponding to direct inhalation for humans. On this basis, the hazard areas for carbon monoxide and fluorine have been analysed, varying the threshold levels of reference. The results of the simulations are the contour plots representing the concentration isopleths at a fixed time for a given threshold level; the $\mathrm{x}$-axis indicates the maximum downwind distance (D) and the $y$-axis the crosswind distance (W) delimiting the hazard area where the toxic gas concentration is at or above the threshold level chosen.

For both substances examined, the hazard areas corresponding to threshold values developed for the same exposure time have been compared; the results obtained for carbon monoxide are shown in Figs 1 and 2. As expected, it is possible to ascertain that larger hazard areas are associated to the threshold levels having lower reference values, corresponding to less heavy effects for people; this is clearly visible, for example, examining the downwind distance obtained using the AEGL-3, which results noticeably greater than distances associated with the others threshold levels. This fact is in agreement with the suggestions of the sector-based scientific literature that, for responding to toxic clouds, recommends to emergency planners the use of the AEGLs, or in a subordinate way the ERPGs values [17]. As previously stated, AEGLs apply to short-term, high-dose exposures, therefore providing information for the decision process by emergency responders and planners which appears most appropriate with respect to exposure limit used for workplace or ambient air, usually developed for long-term and low-dose exposure. It is worth noting, however, that the choice of threshold levels implying larger areas to submit to accident prevention and mitigation measures, may have a significant impact on the socioeconomic aspects of a particular region, therefore necessarily involving a wider and more complex decisional process.

For a conservative estimate of the downwind range for the hazard area, the computational analysis has been carried out with reference to the F2 meteorological condition, which represents the "worst-case" weather condition showing the largest impact areas.

Table 2: Input parameters.

\begin{tabular}{lll}
\hline Pipeline sizes & Section length & $1000(\mathrm{~m})$ \\
& Diameter & $0.40(\mathrm{~m}) \mathrm{I}$ \\
Operating conditions & Temperature & $288.15(\mathrm{~K})$ \\
& Pressure & $40(\mathrm{bar})$ \\
Release condition & Duration & $300 \mathrm{sec}$ \\
Meteorological conditions & Stability classes and wind & $\mathrm{D} ; 5 \mathrm{~m} / \mathrm{s}($ neutral$) ; \mathrm{F} ; 2 \mathrm{~m} / \mathrm{s}$ \\
& speed & $($ very stable) \\
External condition & Roughness length, $\mathrm{z}_{0}$ & $0.03(\mathrm{~m})$ \\
\hline
\end{tabular}




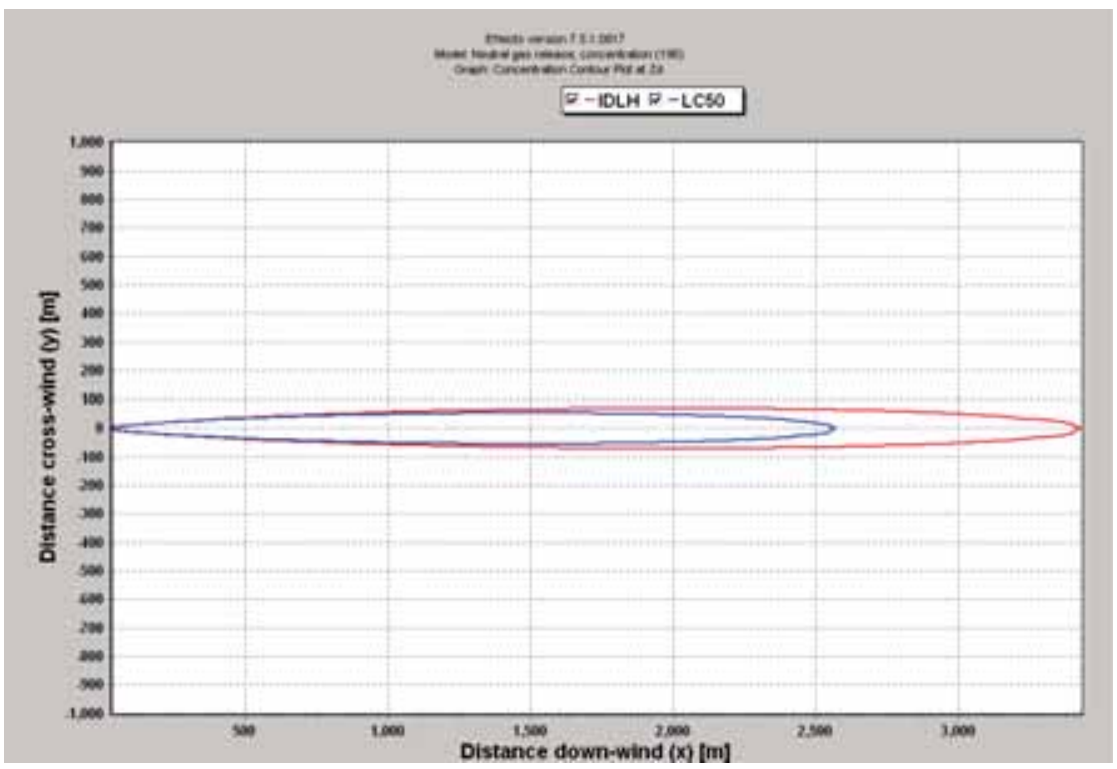

Figure 1: Concentration contour plots for CO corresponding to IDLH and LC50; F2 atmospheric stability class.

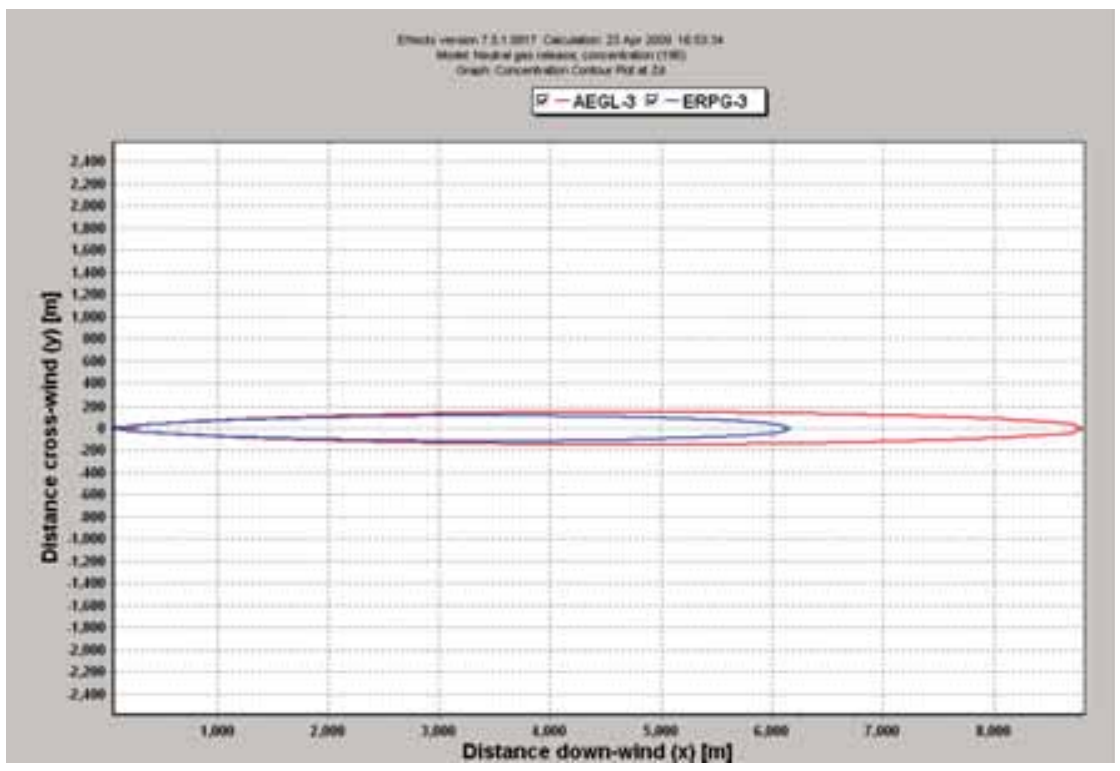

Figure 2: Concentration contour plots for CO corresponding to AEGL-3 and RPG-3; F2 atmospheric stability class.

This is due to the high stability of this class that hampers a fast dispersion of the cloud and to the low values of the wind velocity; this can be seen, for example, in Fig. 3, which shows a comparison between the contour plots corresponding to two set of meteorological conditions adopted in the calculation, respectively D5 and F2, for fluorine. 


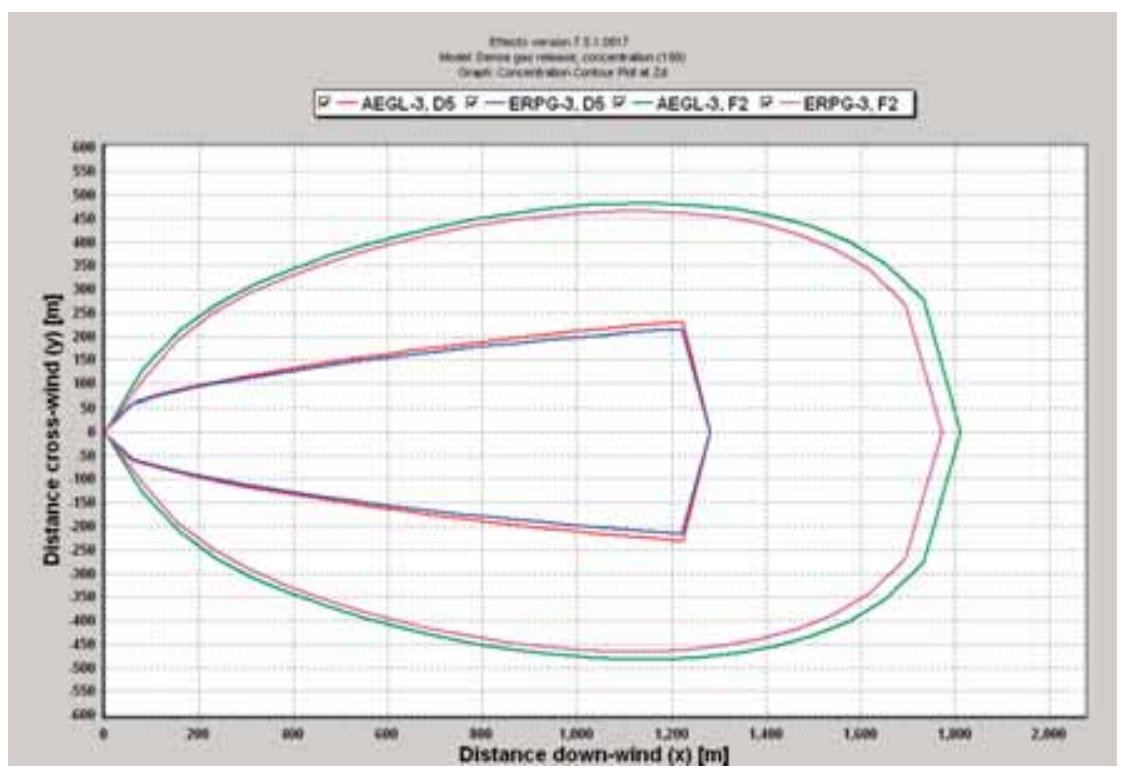

Figure 3: Concentration contour plots for $\mathrm{F}_{2}$ corresponding to AEGL-3 and ERPG-3; D5 and F2 atmospheric stability classes.

Besides the threshold level, also the large variations in physical properties and toxicity between chemicals can produce large variances in both the downwind toxic concentrations as well as the time scale of exposure. With respect to fluorine, carbon monoxide release involves, generally, larger maximum impact distances in downwind directions. In fact, for dense gas, the release will be concentrated in the near field surrounding the source and the downwind dispersion will be delayed until the forces of atmospheric turbulence overcome the gravity force and disperse this cloud in the far field. The net effect is a slower release resulting in a smaller far field hazard area. Moreover, it should be kept in mind that for toxic release the hazard area will depend on wind direction; as it is difficult to predict wind direction in the moment of failure, all possible wind directions should be considered in a conservative analysis, in order to produce circular hazard areas around the failure point as shown in Fig. 4.

\section{CONCLUSION}

Hazard areas caused by toxic releases by pipelines associated with different threshold levels have been evaluated in this study, assuming as a worst case scenario the full-bore rupture of the pipe. In the paper it has been highlighted how the choice of the threshold level of concern could affect the extent of the hazard areas and consequently influence the decisional process concerning the emergency management in the case of accidental toxic release caused either by accident or by deliberate acts of terrorism. Moreover, the obtained results also show how the large difference in physical properties and toxicity of the substances examined produce large variability in the downwind toxic concentrations. This is an on-going study: the liquid and two-phase transport conditions are currently under examination and many other conditions will be considered in future work, for example assuming different release scenarios as well as varying parameters in Table 2 . The estimate of the hazard areas involves a high level of uncertainty, due to uncertainty in the input parameters as well as in the models adopted for 


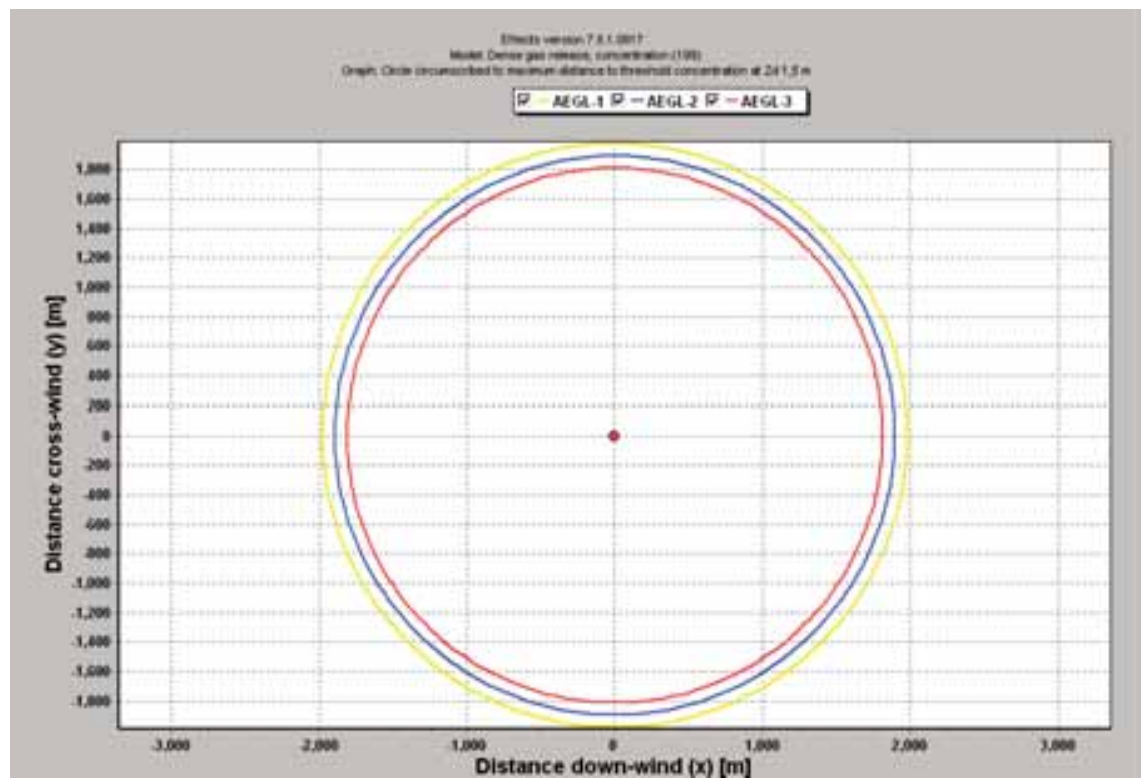

Figure 4: Potential hazard zones for $\mathrm{F}_{2}$ release corresponding to AEGLs; F2 atmospheric stability class.

simulating gas release and dispersion, and to the complexity of chemical-physical phenomena involved in the calculations, which lowers the accuracy and reliability of numerical results. However, this study could still provide useful information for the implementation of pipelines safety and security strategies, guaranteeing at the same that this highly productive means of transportation is not unduly penalized.

NOMENCLATURE

\begin{tabular}{lll}
\hline Symbol & \multicolumn{1}{c}{ Name } & Dimension \\
\hline$A$ & area of cross-section of the pipeline & $\mathrm{m}^{2}$ \\
$\mathrm{~B}$ & half-width of the dispersing cloud & $\mathrm{m}$ \\
$\mathrm{b}$ & parameter of dispersing cloud half-width & $\mathrm{m}$ \\
$\mathrm{C}_{\mathrm{d}}$ & empirical discharge coefficient & - \\
$\mathrm{d}_{\mathrm{p}}$ & diameter pipeline & $\mathrm{m}$ \\
$f$ & pipe friction factor & - \\
$\mathrm{h}_{\mathrm{c}}$ & cloud height parameter & $\mathrm{m}$ \\
$\mathrm{h}_{\mathrm{s}}$ & source height & $\mathrm{m}$ \\
$\mathrm{l}_{\mathrm{p}}$ & pipeline length & $\mathrm{m}$ \\
$\mathrm{P}_{0}$ & initial gas pressure & $\mathrm{Pa}$ \\
$\mathrm{Q}_{0}$ & initial total gas mass in the pipeline & $\mathrm{kg}$ \\
$\mathrm{q}_{\mathrm{s}, 0}$ & initial mass flow rate & $\mathrm{Kg} / \mathrm{sec}$ \\
$\mathrm{t}_{\mathrm{B}}$ & time constant in the Wilson model & $\mathrm{sec}$ \\
$\mathrm{u}_{\mathrm{s}}$ & sonic velocity in the gas & $\mathrm{m} / \mathrm{sec}$ \\
$\mathrm{v}$ & ambient wind velocity & $\mathrm{m} / \mathrm{sec}$
\end{tabular}




$\begin{array}{lll}\mathrm{Z}_{\mathrm{c}} & \text { cloud-height dimensionless parameter } & - \\ \beta & \text { cloud shape parameter } & \mathrm{m} \\ \gamma & \text { specific heat ratio } & - \\ \sigma_{0} & \text { initial gas density } & \mathrm{Kg} / \mathrm{m}^{3} \\ \sigma & \text { dispersion parameter } & \mathrm{m} \\ \sigma_{\mathrm{y}} & \text { standard deviation in the cross-wind direction } & \mathrm{m} \\ \sigma_{\mathrm{z}} & \text { standard deviation in the vertical direction } & \mathrm{m}\end{array}$

\section{REFERENCES}

[1] Papadakis, G., Major Hazard pipelines: A comparative study of onshore transmission accidents. Journal of Loss Prevention in the Process Industries, 12, pp. 91-107, 1999. doi: http://dx.doi.org/10.1016/S0950-4230(98)00048-5

[2] Council Directive 96/82/CE of December 9, 1996 on the control of major accident hazards involving dangerous substances. Official Journal of the European Communities, vol. L 10, Luxembourg, pp.13-33, 1997.

[3] Council Directive 2008/114/EC on the identification and designation of European critical infrastructures and the assessment of the need to improve their protection. Official Journal of the European Communities, vol. L 345, 2008.

[4] National Institute for Occupational Safety and Health (NIOSH). Documentation for Immediately Dangerous to Life or Health Concentrations (IDLH). Available at http:// www.cdc.gov/niosh/idlh/idlh-1.html

[5] American Industrial Hygiene Association (AIHA). Emergency Response Planning Guidelines (ERPGs). Available at http://www.aiha.org/content/insideaiha/ volunteer+ groups/erpcomm.htm

[6] United States Environmental Protection Agency (USEPA). Acute Exposure Guideline Levels (AEGLs). Available at http://www.epa.gov/oppt/aegl/

[7] Centre for Chemical Process Safety of the American Institute of the Chemical Engineers. Guidelines for Chemical Process Quantitative Risk Analysis, New York, 1989.

[8] Wood, M., Pichard, A., Gundert-Remy, U., de Rooij, C. \& Tissot, S.M., The AETL methodology as a potential solution to current challenges associated with the development and use of acute exposure levels in Seveso II applications. Journal of Hazardous Materials, A133, pp. 84-15, 2006.

[9] Bubbico R. \& Mazzarotta, B., Accidental release of toxic chemicals: Influence of the main input parameters on the consequence calculation. Journal of Hazardous Materials, 151, pp. 394-406, 2008.

[10] Gagliardi, R.V. \& Citro, L., A sensitivity analysis on the consequences assessment in case of toxic substance released by pipelines. 5th Int. Conf. On Safety and Reliability, Versita: Warsaw, pp. 39-56, 2008.

[11] Yuhua, D., Huilin, G., Jing'en, Z. \& Yaorong. F., Evaluation of gas release rate through holes in pipelines. Journal of Loss Prevention in the Process Industries, 151, pp. 423-428, 2002.

[12] Committee for the Prevention of disaster, TNO. Yellow Book: Methods for the calculation of physical effects due to release of hazardous materials (liquids and gases). CPR14 (Part 1), 1997.

[13] Lees, F.P., Loss Prevention in the Process Industries Hazard Identification, Assessment and Control, 3rd edn., Butterworths-Heinemann, Elsevier: Texas, USA, 2005. 
[14] Prins Maurits Research Laboratory, TNO. EFFECTS a Software for Hazard Assessment, Netherlands, 1991.

[15] Davis, T.M., Dubois, J., Olcese, A., Uhlig, F., Larivè, J-F. \& Martin, D.E. Performance of European Cross-country Oil Pipelines, CONCAWE, No. 4/07: Brussels, 2007.

[16] D.M. 24 November 1984: Norme di Sicurezza antincendio per il trasporto, la distribuzione, l'accumulo e l'utilizzazione del gas naturale con densità non superiore a 0,8. G.U. $\mathrm{N}^{\circ} 12,1985$.

[17] O'Mahony, M.T., Doolan, D., O'Sullivan, A. \& Hession, M., Emergency planning and the control of major Accident hazards (COMAH/Seveso II) Directive: An Approach to determine the public safety zone for toxic cloud releases. Journal of Hazardous Materials, 154, pp. 355-365, 2008.

This paper has been selected for this special issue but first appeared in WIT Transactions on the Built Environment, Vol 108, () 2009 WIT Press, www.witpress.com, ISSN 1743-3509 (on-line), doi:10.2495/SAFE090161. 